\title{
Solving Geometric Problems by Using Algebraic Representation for Junior High School Level 3 in Van Hiele at Geometric Thinking Level
}

\author{
Abi Suwito ${ }^{1}$, Ipung Yuwono ${ }^{2}$, I Nengah Parta $^{2}$, Santi Irawati ${ }^{2} \&$ Ervin Oktavianingtyas ${ }^{1}$ \\ ${ }^{1}$ Department of Mathematics Education, Teacher and Training Education Faculty, Jember University, Jember, \\ Indonesia \\ ${ }^{2}$ Department of Mathematics, Mathematics and Science Faculty, State University Of Malang, Malang, Indonesia \\ Correspondence: Abi Suwito, School of Management, Northern Canada University, Toronto, Jember University, \\ Jember, Indonesia. Tel: 33-133-0224. E-mail: abi.fkip@unej.ac.id
}

Received: February 1, 2016

Accepted: March 14, 2016

Online Published: September 22, 2016

doi:10.5539/ies.v9n10p27

URL: http://dx.doi.org/10.5539/ies.v9n10p27

\begin{abstract}
This study aims to determine the ability of algebra students who have 3 levels van Hiele levels. Follow its framework Dindyal framework (2007). Students are required to do 10 algebra shaped multiple choice, then students work 15 about the geometry of the van Hiele level in the form of multiple choice questions. The question has been tested levels of validity and reliability. After learning abilities and levels van Hiele algebra, students were asked to answer two questions descriptions to determine the ability of students in answering the question of algebraic geometry punctuated by interviews. From this study illustrated that students who have achieved level 3 van Hiele able to properly solve problems of algebraic geometry in the content by utilizing the deduction reasoning thinking skills to build the structure geometry in an axiomatic system in solving the problems faced. Teachers play an important role in pushing the speed students through a higher level of thinking through the right exercises. Suggestions for further research can develop on different topics but still within the context of algebraic geometry.
\end{abstract}

Keywords: geometry, problem solving, algebra

\section{Introduction}

\subsection{Introduce the Problem}

Algebra is an important material in school mathematics. NCTM (2000) say that algebra is more than moving symbols. Students are required to understand what the concept is, structures that affect the manipulation of symbols and how symbols are used. Algebra student mastery of the material plays an important role in the study of other mathematical material (Carraher et al., 2006). In line with the principle that Kutluca (2013) say geometry is an important material in mathematics. Geomeri is a perennial issue in mathematics education in primary school to higher education (Collier, 1998). Dindyal (2007) says that the students' thinking in geometry also requires a facility with algebra. Van Hiele is someone mathematician who gave birth to the stages of child cognitive development in understanding the geometry known as van Hiele theory. According to the theory of van Hiele someone goes through five levels of hierarchy in the study of geometry (van Hiele, 1999; van de Walle, 1994; D’Augustine \& Smith, 1992; Clements \& Battista, 1992; Jones, 1998).

Level 0 visualizations that students identify, equate, compare and operate on geometrical figures. This level is often called the recognition rate. At this level students are already familiar with geometric shapes, such as square, rectangle, triangle, parallelogram. But geometric shapes known child based solely on visual characteristics or appearance shape as a whole, not in parts. In identifying awake, they often use visual prototypes.

Level 1 analysis, at this level the student to analyze the images in terms of components and relationships between components and discover nature/empirical rules. This level is also called the level of description. At this level the children are already familiar with the properties of geometry based on an informal analysis of the parts up and attributes of components. At this level began much the analysis of the concepts of geometry. Students can recognize and determine the characteristics of the wake by properties. Through observation, experiment, measurement, drawing, and modeling, students can recognize and distinguish the characteristics of a wake. Students see that a structure has certain parts that can be recognized. However, students cannot fully explain the 
relationship between the nature of waking up one with nature wake up the others, and the abstract definition has not been or cannot be understood. An example, children cannot assert that the rectangle is also a parallelogram. Level 2 Deduction informal logic that students found the nature of the relationship between previous/rules by giving or following informal argument. This level is often called the level of abstraction or sorting level. At this level the children can see the relationship between the properties in a single build. For example, wake rhombus, opposite sides parallel to require angles equal opposite. Students are also able to see the relationship between the natures of some wake. An example, a rhombus is a parallelogram because the properties are also owned by the parallelogram rhombus. Students can logically sort the properties built. For example, the students stated that the square is also a rhombus and a rhombus is also a parallelogram. Students can develop a definition and discover the properties built through inductive or informal deduction. Definitions are built not only in the description but are the result of a logical arrangement of the properties defined concept. For example, students can show that the amount of the size of the angles in a quadrilateral is $360^{\circ}$ because every quadrilateral can be decomposed into two triangles each corner $180^{\circ}$, but they cannot explain deductively.

Level 3 Deduction is students' deductive theorem proving and establishing the relationship between network theorems. At this level students are already thinking deductive reasoning as a way to build the geometry of the structure has been conceived in the axiomatic system. This has been demonstrated by the student proves a statement about the geometry by using logical and deductive reason. An example, students have been able to compile evidence if the sides facing a quadrilateral are parallel, the angles are equally big deal. Axiomatic deductive structure complete with base understanding, postulates/axioms, definitions, theorems, and the consequences implicit in informal deduction level, became an object explicit in the thinking of the child at this level. Students have been able to develop evidence more than one way. Reciprocity between necessary and sufficient condition understand. Different between of statement and convers understandable students.

Level 4 Rigor which students set theorem postulates different systems and analyzing/compare systems. At this level students can work in a variety of axiomatic deductive structure. Students can discover the differences between the two structures. Students understand the difference between Euclidean geometry and non-Euclidean geometry. Students understand the axioms underlying the formation of non-Euclidean geometry. Each level in the van Hiele theory, show the characteristics of the thinking of students in learning geometry and understanding the geometric context. The quality of students' knowledge is not determined by the accumulation of knowledge, but rather is determined by the thought processes used. Levels van Hiele thought to be traversed sequentially students. Thus, students must pass a level with mature before heading to the next level. Speed move from one level to the next level more dependent on the content and teaching methods of the age and maturity. Thus, teachers should provide learning experiences that match the students' level of thinking. In this study the thought processes used to use the van Hiele levels of thinking.

\section{Method}

The study was conducted during one week is on 10 to 17 October 2015. The research subjects were taken graders 9 of SMPK John Gabriel Blitar. Beginning of the study is given about the form of algebra that consists of 10 questions, then given a matter of geometry to know students there at a level where the van Hiele levels. Algebra comes from matter who made the researchers, while the matter of geometry refers to the development by Usiskin (1982), Senk (1983, 1985), Patkin (1990, 2010), Patkin and Levenberg (2004). The geometry matter by researchers adapted concerning the triangular and quadrilateral, with many questions there are 15 . The workmanship algebra takes 25 minutes and about geometry takes 30 minutes of which are multiple choices. As for the matter of algebra and geometry in the annex. For scoring a matter of geometry van Hiele level, use the weight of scoring used by Patkin (2014) by scoring at least true that each level 3 or 4 of 5 about to get a score of 1. No. 1-5 states level 1, No. 6-10 states level 2 and No. 11-15 states level 3. So the range of scores for levels 1 through 3 is $0-7$. Each of the weights for level 1 is 1 , the weight for level 2 is 2 and weights to level 3 is 4 so the formula for determining the level of van Hiele is a. $1+$ a. $2+$ a.4, are each a score each level is obtained. Furthermore, after the students work on algebra and geometry, awarded two problem descriptions because of the following form:

1) An isosceles triangle has sides $6 \mathrm{~cm}$ and $15 \mathrm{~cm}$. Calculate the circumference!

2) How many kinds of triangles with a circumference of $10 \mathrm{~cm}$, if the sides are integers?

To question no 1 by researchers adapted from an instrument used Dindyal (2007), while No. 2 was a matter that was developed by researchers. In this study the research subjects answer the problems of algebraic geometry that context that has the ability good algebra and at the level where in the van Hiele. The matter has been validated by three experts in the field of geometry and algebra. Regarding reliability, the question has been tested on different 
groups and shows reliable results. Not only the written test is done to students, researchers also conducted unstructured interviews to learn more about the way of thinking of students at level 3 on the van Hiele levels in solving two problems given geometry.

\section{Results}

After the study, researchers found the students who are at level 3 on the van Hiele level and score algebra is worth 9 out of 10 questions. Here are the questions and the results of student work for about no1.

1) An isosceles triangle has sides $6 \mathrm{~cm}$ and $15 \mathrm{~cm}$. Calculate the circumference!

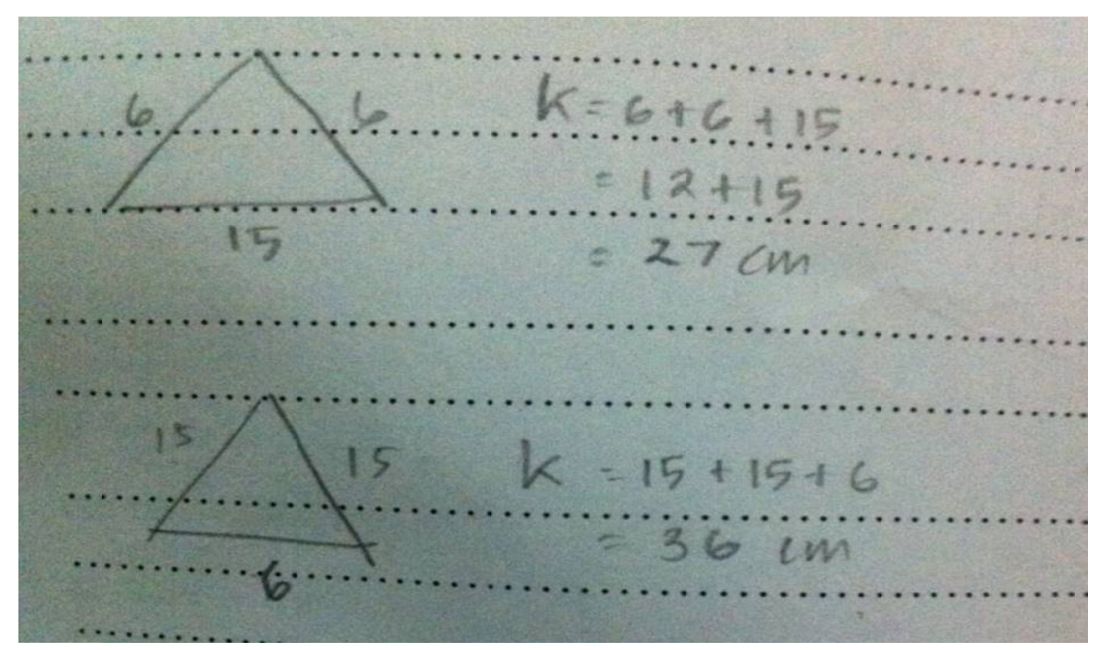

Figure 1. Results of student work for problem No. 1

On the question no 1, there are two answers to students (see Figure 1). The first answer triangle with sides of size $6 \mathrm{~cm}, 6 \mathrm{~cm}$ and $15 \mathrm{~cm}$, while the answer to the second side of the triangle to the size of $6 \mathrm{~cm}, 15 \mathrm{~cm}$ and $15 \mathrm{~cm}$. This student considers it an isosceles triangle. Students use the understanding of the concept of the isosceles triangle with information on the matter. During an interview, the student revealed that the isosceles triangle, there are only two possibilities for the size of the triangle that is the leg side and the side of the pedestal. On the matter given the two sides $6 \mathrm{~cm}$ and $15 \mathrm{~cm}$ sizes that can function both as a foot or hand side of the base triangle so he responded by writing down all the possibilities.

2) How many kinds of triangles with a circumference of $10 \mathrm{~cm}$, if the sides are integers?

The students' answers to question No. 2 there are 4 types (see Figure 2). All types of triangles depicted is isosceles triangles of different sizes. Students affected by the problem No. 1 so he thought that the matter is still the theme No. 2 an isosceles triangle. Students do not know whether all the answers from the no.1 and all the answers of No. 2 are true. To discover the answer, following an interview with the student.

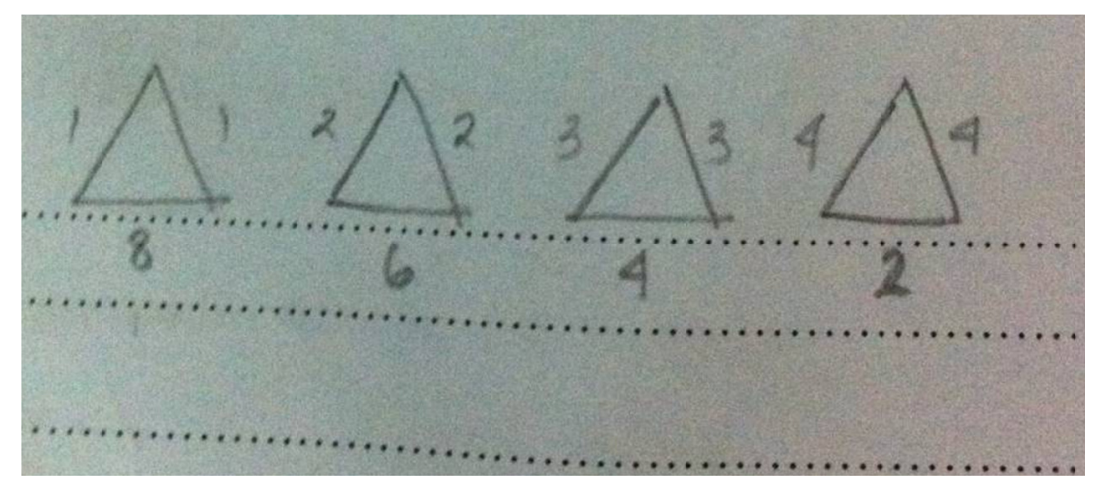

Figure 2. Results of student work for problem No. 2 
G: For the No. 1, how do you get an answer like that?

S: hmmm, how ya ...

G: it's known an isosceles triangle with sides $6 \mathrm{~cm}$ and $15 \mathrm{~cm}$, keep your answers there were two such, try to explain ...!

S: it's known there are two sides, meaning triangles $6 \mathrm{~cm}, 6 \mathrm{~cm}$ and $15 \mathrm{~cm}$. then the second possibility $15 \mathrm{~cm}, 15$ $\mathrm{cm}$ and $6 \mathrm{~cm}$.

G: hmm so yes ... yes, describe all triangles that try. How can it be ...

S: both? (as he started drawing)

G: oh, the triangle first (size $6 \mathrm{~cm}, 6 \mathrm{~cm}$ and $15 \mathrm{~cm}$ ) can ya?

S: Oh, I am wrong size ... (continued drawing again)

Hose 3 minutes

$\mathrm{S}$ : (while showing a picture), it was not so triangle

G: I see ... .try second $(15 \mathrm{~cm}, 15 \mathrm{~cm}$ and $6 \mathrm{~cm})$ try to draw ...

Students start drawing, hose 4 minutes to show images

G: So yes ... the triangle, so the correct answer yes ....

S: yes ...

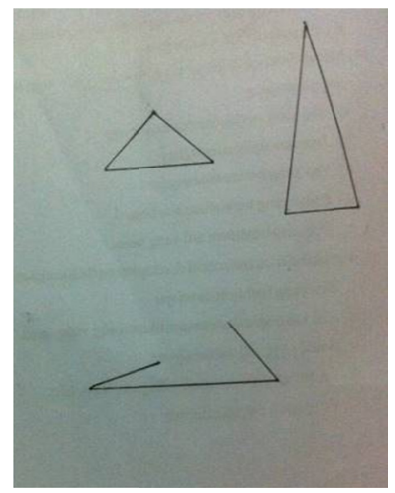

Figure 3. Description students to problem 1 when interviewed

G: first triangle ( $\mathrm{size} 6 \mathrm{~cm}, 6 \mathrm{~cm}$ and $15 \mathrm{~cm}$ ) why it about cannot form a triangle?

S: What ya ... I forget

$\mathrm{G}$ : requirement to establish that any triangle?

$\mathrm{S}$ : what is it, there are three sides

G: there are 3 sides, meaning the first image was triangular ya ... (pointing to the picture)

S: not, because g sides not closed.

G: keep what? Still forget or do not know?

S: I forgot

G: hmmmm ... ok, try number two before seen. Was asked to draw a triangle with a circumference of $10 \mathrm{~cm}$ and its sides are integers.

S: yes ... (with a smile), it turns out my answer could be that this $g$ (pointing to the answer)

G: Why?

S: not closed

G: Why not closed?

S: hmmmm, what? 
G: (pointing to the picture) is not closed??

S: not G: this? S: not G: this? S: closed

G: this?

S: closed

G: the isosceles triangle answered all huh?

S: o yes ...

$\mathrm{G}:$ is there any triangles?

S: no.

G: try, show me ...

2 minutes later

S: not closed hehehe, (moving pictures) as well really not closed ...

G: what size?

S: $1 \mathrm{~cm}, 4 \mathrm{~cm}, 5 \mathrm{~cm}$

G: cooking not closed? Right triangle? Can?

S: can

G: what size?

S: $3 \mathrm{~cm}, 4 \mathrm{~cm}, 5 \mathrm{~cm}$

G: If you add up?

$\mathrm{S}$ : Oh yes ... (with a smile)

G: So from the No. 1 and 2 what conclusions? Let could be a triangle?

$\mathrm{S}$ : comparison of side must be right.

G: side comparison?

S: hehehe, I forgot.

G: So in a triangle (while drawing), for example a triangle $\mathrm{ABC}$ yes, a side length $\mathrm{cm}, \mathrm{b}$ and $\mathrm{c} \mathrm{cm}$. Terms to be triangular, what condition? Suppose $\mathrm{a}$ and $\mathrm{b}$ are the shorter sides of $\mathrm{c}$.

$\mathrm{S}$ : ooooo, $\mathrm{a}+\mathrm{b}$ is greater what is smaller than $\mathrm{c}$ ?

G: behold what?

S: smaller

G: smaller?

S: bigger,

G: see answer No. 2. (Refer picture) is smaller $1 \mathrm{~cm}, 1 \mathrm{~cm}$ and $8 \mathrm{~cm}$ long. could be a triangle?

S: no, so $a+b \geq c$ (he wrote as in Figure 4)

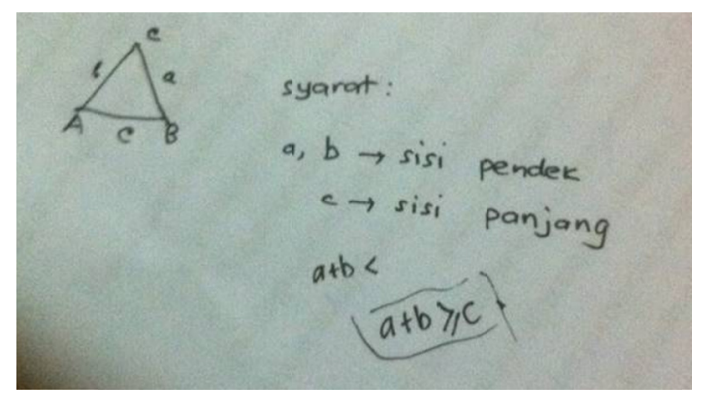

Figure 4. Student writing algebra terms shape size can be side for triangle 
G: yes it is a requirement to be a triangle. Larger or the same as?

S: greater

G: see?

S: yes (smiling).

From the above conversation can be traced student working on regardless of whether the written requirement to form a triangle or not. Students write down the answers if it qualifies a circumference of a triangle, which is if the three sides would meet the size of the sum in question. Through answers written and attested by the drawing, the students begin to understand what is meant in the matter. Originally from interviews no.1 is still not visible, then proceed to the second question, the students begin to understand. Began to understand that there is some measure of triangles that cannot form a triangle, it is not enough simply consist of three sides only. After interference eventually students can write in algebraic form the sides of triangle size requirements in order to form a triangle. Writing in the algebra is also seen from the results of work that has been written before. Research conducted Burger and Shaughnessy (1986) states that the level of junior high school students in learning to think with the highest geometry 2 (deduction informal) and most are at level 0 (visualization). This statement is also supported by the opinion Walle (1994) which states that the majority of junior high school students are at the level of 0 (visualization) to level 2 (deduction informal). But in this study, there was a junior high school students who achieve level 3 (deduction) at the level of thought van Hiele. At the level of deduction, students are already thinking reasoning deduction as a way to build the geometry of the structure has been conceived in the axiomatic system. A student classified as level 3 (deduction), has been able to build a long relationship structure to the side of a triangle can be algebraically, although the direction of the teacher to obtain it. This is consistent with the belief Van Hiele (in Buhari, 2011) that cognitive development in geometry can be accelerated by learning. By using appropriate learning methods, teachers can guide students from one level to the next level. Teachers play an important role in driving speed through a level. A higher level of thinking that can only be achieved through proper exercises, not through lectures alone. Student learning experience greater influence on the ways of thinking than by a factor of age. With much to learn geometry, mathematical ability of students can be improved. One of the goals of learning geometry is to develop problem-solving skills by using logical thinking and mathematical (Suherman, 2012). Referrals from teachers in this study were able to stimulate students to more accurately locate the nature or terms of the size of the side to form a triangle then expressed in algebraic form. Is closely connected with algebraic geometry. Among the Pythagorean theorem and trigonometric equations associated with a right-angled triangle, the equations of the side length, area and perimeter of a flat wake, wake up the volume of a space which are all expressed in algebraic form. This close relationship is also a link between the ability of geometry to algebra students' abilities. Students who are proficient in geometry material, often do not experience much difficulty in solving problems related to algebra, and vice versa.

\section{Discussion}

Students at level 3 to level van Hiele has a good ability to solve problems of algebraic geometry in the content by utilizing the deduction reasoning thinking skills to build the structure geometry in an axiomatic system in solving the problems faced. Generally, the level of junior high school kids have the ability van Hiele at the level of 0-2, but with appropriate learning experiences, can help students to improve the ability of thinking so as to achieve a higher level. It takes guidance from the teacher so that students are able to optimize its potential. Problem geometry is closely related to algebra, geometry many problems can be easily solved if changed in the algebra or otherwise.

\section{References}

Buhari, B. (2011). Teori Level van Hiele dalam Pembelajaran Geometri. Retrieved from https://bustangbuhari.wordpress.com/2011/11/27/teori-level-van-hiele-dalam-pembelajaran-geometri/

Burger, W. F., \& Shaughnessy, J. M. (1986). Characterizing the Van Hiele Levels of Development in Geometry. Journal for Research in Mathematics Education, 17(1), 31-48. http://dx.doi.org/10.2307/749317

Carraher, D. W. et al. (2006). Arithmetic and algebra in Early Mathematics Education. Journal for Research in Mathematics Education, 37(2), 87-115.

Clements, D. H., \& Battista, M. T. (1992). Geometry and Spatial Reasoning. In D. A. Grouws (Ed.), Handbook for Research on Mathematics Teaching and Learning (pp. 420-464). Reston, VA: National Council of Teachers of Mathematics. 
Collier, C. P. (1998). Geometry Mathematics Teaching in the Middle School (pp. 316-387). Reston: NCTM.

D’Augustine, C., \& Smith, S. W. (1992). Teaching Elementary Scholl Mathematic. Boston: Harpe Collins Publisher Inc.

Dindyal, J. (2007). The Need for an Inclusive Framework for Students' Thinking in School Geometry, National Institute of Education Nanyang Technology University, Singapore. The Montana Mathematics, 4(1), 73-83.

Jones, K., \& Bills, C. (1998), Visualisation, Imagery, and the Development of Geometrical Reasoning. Proceeding of the British Society for Research into Learning Mathematics, 18(1\&2), 123-128.

Kutluca, T. (2013). The Effect of Geometry Instruction with Dynamic Geometry Software; GeoGebra on van Hiele Geometry Understanding Levels of Students. Global Science Research Journals, 1(1), 1-10.

National Council of Teachers of Mathematics. (2000). Principles and standards for school mathematics. Reston, VA: Author.

Patkin, D. (2014). Global van Hiele (GVH) Questionnaire as a Tool for Mapping Knowledge and Understanding of Plane and Solid Geometry. J. Korean Soc. Math. Educ., Ser. D, Res. Math. Educ., 18(2), 103-128. http://dx.doi.org/10.7468/jksmed.2014.18.2.103

Suherman, Elniati, S., \& Oktorizal. (2012). Peningkatan Level Berpikir Siswa Pada Pembelajaran Geometri Dengan Pendekatan Pendidikan Matematika Realistik. Jurnal Pendidikan Matematika, 1(1), 60-67.

Van de Walle, J. A. (1994). Elementary School Mathematics. New York: Longman.

Van Hielle, P. M. (1999). Developing Geometric Thinking Through activities That Begin with Play. Teaching Children Mathematics, 5(6), 310-316.

Walle, J. (1994). Elementary School Mathematics. New York: Longman.

\section{Copyrights}

Copyright for this article is retained by the author(s), with first publication rights granted to the journal.

This is an open-access article distributed under the terms and conditions of the Creative Commons Attribution license (http://creativecommons.org/licenses/by/4.0/). 